\title{
Combustion of wood-chips in a small-scale fixed-bed boiler: validation of the numerical model through in-flame measurements
}

\author{
Stefania Patronelli ${ }^{\mathrm{a}}$, Marco Antonelli ${ }^{\mathrm{b}}$, Leonardo Tognotti ${ }^{\mathrm{a}}$, Chiara \\ Galletti ${ }^{\mathrm{a}, *}$ \\ ${ }^{a}$ Department of Civil and Industrial Engineering, University of Pisa, Italy \\ ${ }^{b}$ Department of Energy Engineering, Systems, Land and Buildings, University of Pisa, \\ Italy
}

\begin{abstract}
Experimental campaigns and numerical simulations were carried out to investigate the effect of air distribution on the performance of a small-scale fixed-bed boiler fed with biomass. Despite the small dimension of the fire pit, temperature measurements just above it showed a large spatial variation, thus indicating that modeling approaches based on perfectly stirred reactor conditions for the biomass bed are not suited. Moreover these approaches, often used for small boilers, suffer of high uncertainty related to the inlet turbulence levels that affect the mixing of reactants and thus reaction rates. Instead the representation of the biomass bed as a porous medium with defined sources and sinks of chemical species and energy, may provide a cheap and effective strategy to take into account the distribution of the primary air and overcome uncertainties on inlet turbulence. Results are encouraging with a good prediction of the trends of the available measurements. Signif-
\end{abstract}

\footnotetext{
${ }^{*}$ Corresponding author
} 
icant discrepancies were noticed in some locations, hence calling for further efforts to improve the description of the kinetics as well as of the biomass dimensional distribution needed for the definition of the porous medium.

Keywords: Biomass, Porous Model, Computational Fluid Dynamics, Under-feed Stoker

\section{Introduction}

2 7 sions.

8 Among the available technologies, small-scale boilers are appealing for dis-

The use of biomass as renewable energy source is becoming more and more attractive due to the concern about global warming related to greenhouse gas emissions [1] as well as the limited availability of fossil fuel sources [2]. Biomass combustion is one of the main paths to bioenergy, even though it calls for a number of issues related to energy efficiency and pollutant emis-

tributed energy generation as for residential or mini-district heating as well as for carrying out fundamental research [3, 4].

The main operating variables controlling fixed-bed boiler efficiency and pollutant emissions are the thermal input, air excess and distribution. In particular, the secondary to primary air split ratio $\lambda$ is an important variable affecting the system performance [5]. For instance Wiinikka and Gebart [6] investigated experimentally how different air supply strategies influence particulate matter emission from fixed-bed combustion of biomass. Pettersson et al. [7] analyzed the effect of design changes controlling temperature and/or residence time, on the emission performance and characteristics of a laboratory fixed-bed reactor fed with pellet. Recently Khodaei et al. [8] compared 
experimentally two different configurations for the secondary air distribution in a $15 \mathrm{~kW}$ fixed-bed underfeed combustor, showing their large impact on the temperature in the post-combustion zone, as well as on $\mathrm{CO}$ and particulate matter emissions.

All the above works agree on the fact that there is large room of action to improve the available technologies in terms of efficiency and pollutant emissions. This would require comprehensive investigation on the effect of combustion chamber and inlet design, as well as on the operating conditions, including the biomass characteristics.

In this framework, Computational Fluid Dynamics (CFD) tools, that allow solving several transport equations describing the relevant phenomena in complex geometries, may add significant contribution to the system optimization, providing a description of the thermo-chemical field in the whole combustion chamber. However, the application of CFD to biomass-fired boilers is challenging because it requires an appropriate description of the relevant homogeneous and heterogeneous reactions, the turbulent flow, the mass and heat transfer processes (including radiation) and their interactions. Fully multi-phase models have been proposed recently. Among them, LagrangianEulerian model have received some attention because their ability to well deal with phenomena acting at the particle size. In particular, the granular biomass phase can be solved with a discrete element method (DEM) opportunely coupled with CFD for the gaseous phase. Examples of this modeling strategy are provided by Peters and co-authors [9] [10]. However, it is clear how a high level of modeling detail involves too high computational times and resources, often not balanced by the many sources of uncertainties that 
may affect the analysis (e.g., particle size and shape, moisture content, feeding system, etc. ).

For this reason, the most widely used approaches in literature for modeling biomass boilers, are based on single-phase CFD simulations of the gaseous turbulent reactive flow in the freeboard. The impact of the biomass bed is taken into account through boundary conditions (set at inlet of the freeboard CFD model, represented by the top surface of the biomass bed), that are recovered from simplified description of the solid fuel bed $[11,12,13]$.

The first kind of this approach is very simple and consists in using experimental data to define such boundary conditions [14]. However this model requires experimental data above the biomass bed, that sometimes can be difficult to obtain with sufficient spatial and temporal accuracy.

The second approach consists in developing a simplified model of the biomass bed that can be used to derive the boundary conditions for the CFD freeboard model. For instance the biomass bed can be seen as one or a series of interconnected perfectly stirred reactors PSR, in which mass and energy balances are solved with prescribed conversions of all processes which biomass undergoes (evaporation, devolatilization, char oxidation). This may lead to either uniform (in case of a single reactor) or step-wise (zonal) boundary conditions (in case of a series of reactors) [15, 16], consisting of temperature, chemical species flow rate and concentration. Some authors have considered this coupling to be one directional, i.e. the solution of the bed and the freeboard can be performed sequentially by neglecting the effect of the freeboard on the bed. However, some researches argued that the coupling through radiation interaction cannot be neglected and this requires the knowledge of 
the thermo-chemical field in the combustion chamber. Hence iterative procedures have been proposed to evaluate the radiative flux on the bed, needed to solve the energy balance on the PSR network. Logically, also this biomass bed approach requires for a knowledge or a guess of the biomass conversion along the bed. Moreover, a recent work highlighted the importance of a good estimation of the turbulence levels at the interface between the biomass bed and the freeboard [17].

Unfortunately there is still a lack of comprehensive experimental data, that can be employed for an accurate setting of the simplified models; the main difficulty is that these data should be taken above or inside the biomass bed. Moreover, there is also lack of good experimental data set that can be used for CFD modeling validation. Most of the available measurements are confined to the flue gas characterization, whereas in-flame measurements would be needed to better judge the performance of different models. Porteiro et al. $[12,18]$ studied the ignition front of propagation of several biomasses in a one-dimensional fixed-bed combustor. The authors used the results to develop a modeling methodology for the three-dimensional simulation of biomass combustion in packed beds. Girgis and Hallett [19] measured gas and tar concentrations, temperatures and bed properties in an over-feed packed bed to develop a detailed numerical model of devolatilization. Buchmayr et al. $[20,21,22]$ provided detailed information about the spatial distribution of gaseous species above the fuel bed for different air ratios and varying fuel moisture in a small, air-staged, wood-chip boiler with a nominal power of 40 $\mathrm{kW}$.

In the present work, the combustion of wood-chips in a small-scale fixed- 
bed boiler is investigated. A joint experimental and CFD modeling activity has been planned to study the effect of primary to secondary air ratio on the temperature and chemical species fields. It is shown that the biomass bed treatment plays a major role, not only on the near bed region but also on the whole chamber. A simple model is proposed to better take into account the effect of primary air distribution.

\section{Biomass boiler}

\subsection{Experimental plant}

The investigated plant is located at the Biomass to Energy Research Center (CRIBE) in Pisa, Italy. The system is constituted by a fixed-bed combustion chamber (nominal thermal input of $140 \mathrm{~kW}$ ), a flue gas to oil heat exchanger and a flue gas cleaning system, that removes the particulate matter. The oil coming from heat exchanger is fed to a Kettle-type boiler to generate steam. A scheme of the plant is reported in Figure 1a.

[Figure 1 about here.]

\subsection{Fixed-bed boiler}

The boiler belongs to the under-feed stoker type. Biomass is fed into the combustion chamber (Figure 1b) through a screw conveyor while primary air is injected through 68 rectangular holes placed laterally with respect to the fire pit. The fixed-bed length is about $0.6 \mathrm{~m}$ while the whole chamber is approximately $1.9 \mathrm{~m}$ long. The original boiler configuration has been modified specifically by adding an inverter to control the air blower speed and a secondary air injection system; this consists of a carbon steel manifold 
where the secondary air is supplied through 9 injection pipes bended at the upper edge (Figure 1b).

\subsection{Instruments}

The biomass boiler was equipped with a control and measuring system to monitor temperature and gas composition both above the biomass bed and at the boiler outlet. A $20 \mathrm{~Pa}$ of depression inside the combustion chamber was maintained thank to a secondary fan, placed at the flue gas outlet and controlled by a pressure sensor. The flow rates of primary and secondary air were measured through two hot wire flow-meters. The total air flow rate was regulated through the blower rotational speed, whereas the primary and secondary air flow rates were regulated by means of two valves. The concentration of chemical species in the flue gases $\left(\mathrm{CO}_{2}, \mathrm{CO}, \mathrm{O}_{2}\right)$ was acquired by means of an Environment S.A. station, equipped with infrared, paramagnetic, flame ionization, and chemiluminesence detectors. Details about the control and measuring system can be found in previous works [23, 24].

A shielded probe was built on purpose to acquire the flue gas temperature upstream of the heat exchanger, as shown in Figure 1b. Moreover, the spatial variation of temperature was also determined by using several thermocouples placed just above the biomass bed (of K, J and T type); their location is depicted in Figure 2.

[Figure 2 about here.]

\subsection{Experimental campaigns}

Different operating conditions, i.e. equivalence ratio and secondary to primary air flow ratio, were used to investigate their effect on the perfor- 
mance of the combustion process. Experimental campaigns were carried out using wood-chips of different kinds of wood (poplar, beechwood, chestnut) and sizes. In this paper only the campaign performed with poplar wood-chips with coarse grain size will be considered. Biomass was fully characterized by proximate and ultimate analysis, whereas particle size, $d_{p}$, also known as the average value of the particle size distribution, was determined through gravimetric methods using different sieves. The biomass properties are summarized in Table 1.

[Table 1 about here.]

Of all the tests, only four runs with the same air mass flow (i.e $m_{a, t o t}=$ $0.10 \mathrm{~kg} / \mathrm{s}$ ) and different primary to secondary air flow ratio, i.e. $\lambda=\frac{\dot{m}_{s a}}{\dot{m}_{p a}}$ were chosen. Process parameters, species concentration and temperature of the flue gas and combustion air are reported in Table 2.

[Table 2 about here.]

The biomass flow rate $\dot{m}_{b}$ was estimated from a global material balance on the boiler, knowing the oxygen mass fraction $Y_{O_{2}}$, free in the flue gas and the total air mass flow $\dot{m}_{a, t o t}$ which were effectively measured (see Section2.3). The resulting system of equation is:

$$
\left\{\begin{array}{l}
\dot{m}_{a, t o t}=\dot{m}_{a, s t}+\dot{m}_{a, \text { exc }} \\
\dot{m}_{a, s t}=\dot{m}_{b} \cdot\left(11.5 X_{C}+34.48 X_{H}-4.3 X_{O}\right) \\
\dot{m}_{a, \text { exc }}=\frac{Y_{O_{2}, \text { free }}}{0.23} \cdot \dot{m}_{f} \\
\dot{m}_{f}=\dot{m}_{b} \cdot\left(X_{C}+M+X_{H}+X_{O}\right)+\dot{m}_{a, t o t}
\end{array}\right.
$$

that can be solved to determine the biomass flow rate as:

$$
\dot{m}_{b}=\frac{\dot{m}_{a, t o t} \cdot\left(1-\frac{Y_{O_{2}, \text { free }}}{0.23}\right)}{\left(11.5 X_{C}+34.48 X_{H}-4.3 X_{O}\right)+\frac{Y_{O_{2}, \text { free }}}{0.23} \cdot\left(X_{C}+M+X_{H}+X_{O}\right)}
$$


In the above equations $X_{C}, X_{N}, X_{H}$ and $X_{O}$ are the mass fraction of $\mathrm{C}$, $\mathrm{N}, \mathrm{H}$ and $\mathrm{O}$, respectively, in the biomass, whereas $M$ represents the mass fraction of the moisture. $\dot{m}_{a, s t} \dot{m}_{a, e x c}$ are the stoichiometric and excess air flow rates, respectively, whereas $\dot{m}_{f}$ is the flue gas mass flow rate.

The temperatures collected above the biomass bed are shown in Table 3 along with the errors, that were estimated as the standard deviation of the recorded temperature series. It can be observed a strong variation of the absolute values with the spatial coordinate.

[Table 3 about here.]

\section{Numerical model}

\subsection{Methodology}

The numerical model is based on a single-phase reactive flow simulation for the freeboard that is coupled with the biomass bed model. This is taken into account through two different approaches.

The first approach is similar to the one proposed in a previous work for different experimental campaigns [17]. Practically the biomass bed is excluded from the computational domain and proper boundary conditions are set at the interface between the bed and the combustion chamber that represents an inlet for the CFD model of the freeboard. As mentioned in the Introduction, this is also the most widely used strategy for the simulation of small-scale biomass boilers. The boundary conditions, consisting of temperature, chemical species concentration and flow rates, are calculated through an off-line sub-model of the biomass bed. 


\subsection{Biomass bed model}

This model conceives the bed as a perfectly stirred reactor in which biomass undergoes evaporation, devolatilization and char oxidation. The assumption of a single reactor is justified by the relatively small dimensions of the bed. Hence, the combustion processes occurring within this reactor can be described as follows:

$$
\begin{gathered}
\text { Biomass } \rightarrow \text { Moisture }+ \text { Dried Biomass } \\
\text { Dried Biomass } \rightarrow \text { Volatiles }+ \text { Char } \\
\text { Char }+\mathrm{O}_{2} \rightarrow \mathrm{CO}_{2}
\end{gathered}
$$

The volatiles are treated here as a single pseudo-component $\mathrm{C}_{x} \mathrm{H}_{y} \mathrm{O}_{z} \mathrm{~N}_{w}$, whose formula is derived from the wood-chip proximate and ultimate analysis. It is assumed that char is completely oxidized into $\mathrm{CO}_{2}$. This hypothesis is considered satisfactory because the $\mathrm{CO}$ concentration is negligible due to low temperature. Indeed the $\mathrm{CO}$ to $\mathrm{CO}_{2}$ ratio can be estimated from the following correlation [25]

$$
\frac{\mathrm{CO}}{\mathrm{CO}_{2}}=2500 \cdot \exp \left(\frac{6420}{T_{p}}\right)
$$

2500 where $T_{p}$ is the biomass bed temperature. Hence, the products derived from evaporation, devolatilization and char oxidation, along with the $\mathrm{N}_{2}$ and excess $\mathrm{O}_{2}$ of the primary air, represent the inlet species to the freeboard CFD model.

The inlet turbulence conditions to the freeboard CFD model may strongly affect the mixing of reactants (volatiles and air) and thus the resulting thermochemical field [17]. Hence, in this work two different methods are proposed 
in the framework of the first approach to estimate the inlet turbulence levels, leading to model \#1 and model \#2.

In the second approach, model \#3, the biomass bed is embedded in the CFD domain and considered as a porous medium. The main idea is that this kind of treatment may help removing the uncertainty related to the assumption on the turbulence levels and may also give some details on the air distribution, still preserving a low computational effort in comparison with fully multi-phase models.

\subsection{Freeboard model}

\subsubsection{Domain and numerical grid}

The computational domain for the freeboard extends from the biomass bed to the lower edge of heat exchanger which is kept out from the domain. Thanks to the symmetry, just half boiler could be modeled as shown in Figure 3 indicating also surfaces for the boundary conditions.

Two different domains were created for the main body and the air manifold. The latter was represented in details to estimate the differential air flow through the 9 injection pipes. A grid independency study was carried out using 4 unstructured grids (with number of elements ranging from 1000k to $2300 \mathrm{k}$ ) and 4 structured grids (with number of elements ranging from 600k to 1200k) generated with ANSYS ICEM CFD v. 16. All of the grids developed present finer cells where higher gradients are expected, as in the vicinity of the secondary air nozzles. The fully structured grids were generated using a multi-block approach and O-grid strategy for circular and semicircular surfaces. Among the grids, the structured grid with 800k cells (see Figure 3b) was chosen as it provided accurate results and good convergence. The domain 
for the biomass bed used in model \#3 was discretized by using a structured grid with 10k hexaedral cells and attached to the previous geometry. Primary air inlet holes are included in the final geometry as shown in Figure 4.

[Figure 3 about here.]

[Figure 4 about here.]

\subsubsection{Physical model}

The numerical model was developed with ANSYS Fluent v 16. FavreAveraged Navier-Stokes (FANS) conservation equations of continuity, momentum, energy and species transport were solved for the single-phase reactive turbulent flow. Steady-state simulations with a pressure-based solver were performed using a second upwind interpolation scheme and a SIMPLE algorithm for the pressure-velocity coupling.

The conservation equations are:

$$
\begin{gathered}
\nabla(\bar{\rho} \widetilde{\mathbf{u}})=0 \\
\nabla(\bar{\rho} \widetilde{\mathbf{u}})=-\nabla \bar{p}+\nabla \cdot\left(\mu+\mu_{t}\right)\left[\left(\nabla \widetilde{\mathbf{u}}+\nabla \widetilde{\mathbf{u}}^{T}\right)-\frac{2}{3} \nabla \cdot \widetilde{\mathbf{u}} \mathbf{I}\right] \\
\nabla\left(\bar{\rho} \widetilde{\mathbf{u}} \widetilde{Y}_{k}\right)=\nabla \cdot\left[\left(\rho D_{k}+\frac{\mu_{t}}{S c_{t}}\right) \nabla \widetilde{Y}_{k}\right]+\bar{\omega}_{k} \\
\nabla(\bar{\rho} \widetilde{\mathbf{u}} \tilde{h})=\nabla \cdot\left[\left(\rho \alpha+\frac{c_{p} \mu_{t}}{P r_{t}}\right) \nabla \widetilde{T}\right]-\nabla \cdot\left[\sum_{k} h_{k}\left(\rho D_{k}+\frac{\mu_{t}}{S c_{t}}\right) \nabla \widetilde{Y}_{k}\right]+\bar{Q}_{r}
\end{gathered}
$$

where $\widetilde{\varphi}$ represents the Favre-average of the $\varphi$ variable, i.e. $\widetilde{\varphi}=\frac{\overline{\rho \varphi}}{\bar{\rho}}$. In above equations, $\rho$ is the density, $\mathbf{u}$ is the velocity vector, $p$ is the pressure, 
$Y_{k}$ is the mass fraction of the k-th chemical species, $h$ is the enthalpy and $T$ is the temperature. The superscript $T$ indicate the transpose matrix. $\mu$ and $\mu_{t}$ are the dynamic and turbulent viscosity respectively, $D$ is the diffusivity, $\alpha$ is the thermal conductivity and $c_{p}$ is the specific heat. $S c_{t}$ and $P r_{t}$ are turbulent Schmidt and Prandtl number, respectively. $\omega_{k}$ is the source or sink of the k-th chemical species due to reactions, whereas $Q_{r}$ is the enthalpy source due to radiation.

The turbulent viscosity is estimated through the standard $\kappa-\varepsilon$ turbulence model as:

$$
\mu_{t}=\bar{\rho} C_{\mu} \frac{k^{2}}{\varepsilon}
$$

where the constant $C_{\mu}$ is $0.09 . k$ and $\varepsilon$ are the turbulent kinetic energy and its dissipation, that are evaluated through two additional transport equations:

$$
\begin{gathered}
\nabla(\bar{\rho} \widetilde{\mathbf{u}} k)=\nabla \cdot\left[\left(\mu+\frac{\mu_{t}}{\sigma_{k}}\right) \nabla k\right]+\mu_{t}\left(\nabla \widetilde{\mathbf{u}}+\nabla \widetilde{\mathbf{u}}^{T}\right):\left(\nabla \widetilde{\mathbf{u}}+\nabla \widetilde{\mathbf{u}}^{T}\right)-\bar{\rho} \varepsilon \\
\nabla(\bar{\rho} \widetilde{\mathbf{u}} \varepsilon)=\nabla \cdot\left[\left(\mu+\frac{\mu_{t}}{\sigma_{\varepsilon}}\right) \nabla \varepsilon\right]+\bar{C}_{\varepsilon 1} \frac{\varepsilon}{k}\left(\nabla \widetilde{\mathbf{u}}+\nabla \widetilde{\mathbf{u}}^{T}\right):\left(\nabla \widetilde{\mathbf{u}}+\nabla \widetilde{\mathbf{u}}^{T}\right)-\bar{\rho} C_{\varepsilon 2} \frac{\varepsilon^{2}}{k}
\end{gathered}
$$

where $C_{\varepsilon 1}=1.44$ and $C_{\varepsilon 2}=1.92 . \sigma_{k}=1.0$ and $\sigma_{\varepsilon}=1.3$ are the turbulent Prandtl numbers for $k$ and $\varepsilon$, respectively.

The average chemical source term due to reaction, i.e. $\bar{\omega}_{k}$, is estimated through the Eddy Dissipation Model (EDM), that assumes reactions to be infinitely fast and thus the rate is determined by the turbulent mixing of reactants. Accordingly, the model takes the minimum of the rates determined by reactants or products to evaluate the source of the k-th species as:

$$
\overline{\omega_{k, r}}=\nu_{k_{r}}^{\prime} W_{k} A \bar{\rho} \frac{\varepsilon}{k} \min \left(\frac{\widetilde{Y_{R}}}{\nu_{R, r}^{\prime} W_{R}}, B \frac{\sum_{P} \widetilde{Y_{P}}}{\sum_{j} \nu_{j, r}^{\prime} W_{j}}\right)
$$


where $A=4$ and $B=0.5$ are empirical constants, $\nu$ are the stoichiometric coefficients, $W$ the molecular weights and the subscript $R$ and $P$ indicate reactants and products. Volatiles are treated as a pseudo-component and their oxidation is described by a two-step reaction scheme as:

$$
\begin{gathered}
\mathrm{C}_{1.02} \mathrm{H}_{2.04} \mathrm{O}_{0.96} \mathrm{~N}_{0.0113}+ \\
0.53 \mathrm{O}_{2} \rightarrow 1.02 \mathrm{CO}+1.02 \mathrm{H}_{2} \mathrm{O}+0.0056 \mathrm{~N}_{2} \\
\mathrm{CO}+0.5 \mathrm{O}_{2} \rightarrow \mathrm{CO}_{2}
\end{gathered}
$$
tion in g $[13)$ 25 to 26

. 28 $\mathrm{t}$ o 1

2 
be required to consider more complex kinetic schemes that, logically, will demand for finite rate turbulence-chemistry interaction treatment.

Radiation was taken into account through the $\mathrm{P} 1$ model and the radiative properties of the gas phase was estimated with the Weighted Sum of Gray Gases model with coefficient from Smith et al. [31].

\subsubsection{Boundary conditions}

The inlet of the freeboard plays an essential role as it stems directly from the biomass bed model. This is effectively an inlet surface for model \#1 and $\# 2$, whereas it is an interface for model $\# 3$, In model \#1 and \#2, a mass flow condition is set to such inlet with the flow directed normally to the surface. The flow rate, composition and temperature are estimated through the biomass bed model based on a single PSR, that has been described in Section 3.2. The mean temperature at the inlet surface $T_{\text {inlet }}$ is computed through an energy balance for the PSR, as:

$$
\begin{aligned}
& \dot{m}_{\text {char }} L H V_{\text {char }}+\dot{m}_{p a} \int_{T_{\text {ref }}}^{T_{a}} c_{p_{a}}(T) d T= \\
& \dot{m}_{v o l}\left(\Delta H_{\text {dev }}+\int_{T_{\text {ref }}}^{T_{\text {inlet }}} c_{p_{\text {vol }}}(T) d T\right)+\dot{m}_{\mathrm{CO}_{2}} \int_{T_{\text {ref }}}^{T_{\text {inlet }}} c_{p_{\mathrm{CO}_{2}}}(T) d T+ \\
& +\dot{m}_{\mathrm{H}_{2} \mathrm{O}}\left(\int_{T_{\text {ref }}}^{T_{\text {ev }}} c_{p_{\mathrm{H}_{2} \mathrm{O}, l}}(T) d T+\lambda_{\mathrm{H}_{2} \mathrm{O}}\left(T_{e v}\right)+\int_{T_{\text {ref }}}^{T_{\text {inlet }}} c_{p_{\mathrm{H}_{2} \mathrm{O}, v}}(T) d T\right)+ \\
& \quad+\dot{m}_{\mathrm{O}_{2}} \int_{T_{\text {ref }}}^{T_{\text {inlet }}} c_{p_{\mathrm{O}_{2}}}(T) d T+\dot{m}_{\mathrm{N}_{2}} \int_{T_{\text {ref }}}^{T_{\text {inlet }}} c_{p_{\mathrm{N}_{2}}}(T) d T+Q_{r}
\end{aligned}
$$

where the subscript $p a$ indicates the primary air. An iterative procedure is necessary to take into account of the radiative transfer $Q_{r}$ between the biomass bed and the freeboard. Indeed, this radiative transfer depends on the composition and temperature of the gas phase as well as of the walls, so 
it should be updated while proceeding with the simulations [15].

The boundary conditions for the $k$ and $\varepsilon$ equations were obtained according to two different assumptions. In model \#1 the flow was represented as a fully developed flow from a pipe of diameter equal to the hydraulic diameter of the inlet section (i.e. $D_{h}=0.25 \mathrm{~m}$ ) and a turbulence intensity $T I=5 \%$ is considered. The relations that express $k$ and $\varepsilon$ in this case are the following:

$$
\begin{gathered}
k=\frac{3}{2}\left(u_{a v g} T I\right)^{2} \\
\varepsilon=C_{\mu}^{\frac{3}{4}} \frac{k^{\frac{3}{2}}}{\ell} \\
\ell=0.07 D_{h}
\end{gathered}
$$

where $u_{a v g}, T I, \ell$ and $D_{h}$ are the average velocity magnitude, the turbulent intensity, the turbulent length scale and the hydraulic diameter of the inlet surface, respectively.

In model \#2 the flow entering the fluid domain was assumed to be like to the flow downstream of a perforated plate, with its length scale equal to the hole hydraulic diameter (i.e., $\ell=0.008 \mathrm{~m}$, estimated from the biomass mean diameter $d_{p}=13 \mathrm{~mm}$ and void fraction $\left.\epsilon=0.5\right)$ :

$$
\ell=D_{h, h o l e}=\frac{2}{3} \frac{\epsilon}{(1-\epsilon)} d_{p}
$$

In such a case the turbulence intensity at the exit of the packed bed was much higher, i.e. $T I=35 \%$, than of model $\# 1$. This value was deduced from the work of Hall and Hiatt [32] who measured the turbulence intensity out of a ceramic foam.

In model \#3 a porous domain was used to represent the biomass bed region that was hence included in the CFD model. The transport equations in the 
porous medium contain additional source terms for mass, species, energy and radiation. The basic idea is to use these volumetric source terms to model the drying, the volatile release and the char combustion occurring inside the bed. Basically these source terms are positive for the volatiles, for $\mathrm{H}_{2} \mathrm{O}, \mathrm{CO}_{2}$ and energy and negative for $\mathrm{O}_{2}$, that is consumed for char oxidation. The source terms used for the 4 experimental runs are reported in Table 4 . The source terms were not given uniformly across the entire volume of the fire pit, as a maldistribution of the biomass in the fire pit was observed experimentally; in particular the screw conveyor was unable to push the biomass up to the opposite edge of the fire pit with respect to the feeding. Hence, as attempt was made to take this phenomenon into account by setting the entire sources up to $85 \%$ of the fire pit length; then in the last $15 \%$ of length such sources were let to decrease linearly to zero. This was performed through a subroutine written in $\mathrm{C}++$ (User Defined Function, UDF) which was coupled to the CFD code.

\section{[Table 4 about here.]}

The porous medium zone has been assigned by defining a source term $S_{i}$ in the momentum equation in the i-th direction [33]:

$$
S_{i}=-\left(\frac{\mu}{\alpha_{p}} \tilde{u}_{i}+\frac{1}{2} C_{2} \rho|\tilde{u}| \tilde{u}_{i}\right)
$$

The permeability of the bed $\alpha_{p}$ and the inertial coefficient $C_{2}$, which was considered to be isotropic, are estimated as:

$$
\begin{gathered}
\alpha=\frac{d_{p}^{2}}{150} \frac{\epsilon^{3}}{(1-\epsilon)^{2}} \\
C_{2}=\frac{3.5}{d_{p}} \frac{(1-\epsilon)}{\epsilon^{3}}
\end{gathered}
$$


These $\alpha_{p}$ and $C_{2}$ parameters are used to calculate viscous and inertial resistances, respectively.

A mass-flow inlet boundary condition is assigned to the rectangular holes (as seen in Figure 4) for the injection of primary air. The mass flow and the temperature of the primary air were available experimentally.

For the outlet surface, the pressure outlet condition was assigned with a value that matches the depression of the suction fan and an emissivity of 0.35 which is typical for flue gas. Regarding the wall a no-slip condition is imposed for the velocity and a zero-flux is assigned for the chemical species. The wall temperature was set equal to the outlet temperature except for the chamber bottom for which adiabatic conditions are applied. An emissivity of 0.8 was set to the chamber refractory walls, whereas a value of 0.7 was set to the secondary air injection system, made of steel. In model \#3 an emissivity of 0.8 was employed for the porous bed wall.

\section{Results}

In the following section, predictions are analyzed and discussed. First, a comparison between the three biomass models is made to shed light into their influence on the resulting field. Subsequently, the effect of the air split ration $\lambda$ on the boiler performance is investigated through model \#3.

\subsection{Effect of biomass bed model}

Figure 5 shows the distribution of temperature the longitudinal section along the middle plane of the boiler for CFD model \#1, \#2 and \#3, for the experimental test \#1 (see Table 2). This run was chosen as characterized by the absence of secondary air (i.e $\lambda=0$ ); hence it is possible to observe 
more clearly how the inlet turbulence conditions affect the thermal field. Model \#1, according to which the bed interface is alike the outlet section of a rectangular pipe to estimate the turbulence levels (see paragraph 3.3), shows almost no reaction due to volatiles oxidation above the biomass bed, as can be evinced by the temperature field in Figure 5a. This is due to the low turbulence levels above the bed that are not enough to promote the turbulent mixing of the reactants. Hence the highest temperatures are observed closer to the top walls, where turbulence increases.

[Figure 5 about here.]

A 3D field is reported in Figure 6a where the distribution of temperature is shown at different boiler cross sections. It can be observed how the region above the bed is rather cold, thus in large discrepancy with the experimental evidence, that for this run reports temperatures as high as 1325K (see Table 3) .

Instead, model \#2, that assumes the flow coming from the biomass bed to be like the flow downstream of a perforated plate, is characterized by higher turbulence levels. This leads to a strong turbulent mixing; hence volatiles rising from the bed immediately burn as soon as they get into the freeboard leading to sharp thermal gradients in the close proximity of the inlet surface (see Figure 5a). This is well evident from the cross sections along the boiler (see Figure 6).

[Figure 6 about here.]

It is worth noting that both models \#1 and \#2 lead to an even distribution of temperature above the bed, as shown in Figure 7. There is only 
some variation at the opposite side with respect to the inlet; such variation is due to the influence of the secondary air manifold on the thermal field. The rather uniform distribution is logical as the boundary conditions are homogeneous across the bed; however this is in contrast with the spatial variation of temperature that was pointed out by the experimental measurements. These are reported in the same figure with symbols colored by the value of temperature. The highest values are detected by the first two thermocouples near the center (shown with rhombi), whereas the thermocouples that are placed far away from the injection (both the central and the lateral) measure the lowest temperatures. However, model \#2 provides values of temperatures that are more alike the average value of the measured ones, whereas model \#1 strongly underestimates the temperature field.

[Figure 7 about here.]

In model \#3, where a source of pressure drop is applied and a reactive porous model is used to represent the biomass bed, the distribution in the longitudinal mid-plane of the boiler shows very high temperature above the bed (Figure 5c). Looking at the cross sections in Figure 6c it appears how the flame is located very near the boiler middle plane. This is due to the lateral injection of the primary air that leads to a confluence of such air, and thus of reactions, towards the center.

The performance of this model can be appreciated in Figure 7c, where 3D maps of the bed surface temperature are shown along with the experimental measurement points. It can be observed that model \#3 is able to predict the trend of temperatures near the centerline, where the first two measurements 
show high values, whereas the latter indicate a cold region. The first two lateral temperatures are underestimated whereas the third seems to be well captured.

\subsection{Effect of air distribution}

Model \#3 was applied to test cases \#2, \#3, \#4 characterized by an increasing value of the secondary to primary air flow ratio $\lambda$. The resulting temperature fields are shown in Figure 8 and Figure 9. The effect of secondary air is to push the reaction region close to the biomass bed. Indeed, with increasing $\lambda$ from $\lambda=0$ (see Figure 9a) to $\lambda=0.8$ (Figure 9b) the temperatures near the bed appear higher due to the enhanced turbulent mixing that promotes reactions. However, with further increasing the secondary air up to $\lambda=1$ (see Figure 9c) temperatures seem to diminish; in this case the secondary air flow rate is too high that the presence of a cold jet prevails on the increase turbulent mixing, thus leading to a rather cold region above the bed near the center.

[Figure 8 about here.]

[Figure 9 about here.]

The spatial temperature distribution above the bed for the different $\lambda$ can be appreciated in the 3D plots of Figure 10 where also experimental measurements are reported.

[Figure 10 about here.]

A quantitative comparison for all thermocouples and $\lambda$ values is reported in Figure 11. 
[Figure 11 about here.]

The first (LL, close to the inlet) and second (LC) temperatures near the axis are well captured by the model for almost all $\lambda$ as can be observed from Figure 11d and Figure 11e. The third temperature on the axis (LR) (see Figure 11f) is, instead, largely overestimated for all $\lambda$ values. The experimental measurements record very low temperatures in such region; this is believed to be partly imputed to a maldistribution of the biomass on the fire pit. In particular it was observed that the screw conveyor was unable to push the biomass up to cover the whole fire pit. As mentioned in Section 3.3.3, this was partly taken into account by decreasing the sources of energy and species in such location, but logically this procedure should be revised and optimized. In addition, it is worth noting that, according to Figure 7c and Figure 10, such measurement location is characterized by very large temperature gradients, so an uncertainty on the probe position could largely affect the results and agreement between experiments and predictions. As for the lateral thermocouples (see Figure 11a-c), a systematic underestimation of temperature was observed. This may indicate an erroneous consideration of the pressure drops in the biomass bed model.

The comparison between the predicted and measured temperatures upstream of the heat exchanger is shown in Figure 12a that indicates a very good agreement, with some deviation only in the case of just primary air $(\lambda=0)$. The comparison between predicted and measured concentrations of $\mathrm{O}_{2}$ and $\mathrm{CO}_{2}$ are shown in Figure 12b and Figure 12c, respectively, along with the experimental errors. The trend is well captured and the agreement can be considered satisfactory especially taking into account the large sources of 
uncertainty that may affect the comparison.

[Figure 12 about here.]

\section{Conclusions}

Experimental measurements above the fire pit of a small-scale biomass boiler indicated a strong spatial variation of temperature. This cannot be taken into account with the usual numerical modeling strategy of small boilers, that is based on a PSR model of the biomass bed that is coupled with the CFD model of the reacting gas phase in the freeboard. Although such strategy is extensively used, this work has shown that results are largely affected by the assumption on the inlet turbulence levels that influence the turbulent mixing of the reactants. To overcome this issue, the present work suggests to use a porous domain for the biomass bed region by imposing sources (or sinks) of energy and chemical species. In this manner the real feeding of the primary air could be also taken into account.

Results indicate that the model is capable of describing a spatial variation of the temperatures and to correctly predict that the highest ones are located near the axis due to the confluence of primary air, generated by its lateral feeding. The trends with increasing the secondary to primary air mass flow ratio are captured, even though there are some regions that show significant discrepancies. The reasons for such discrepancies have to be further investigated; however it is worth keeping in mind that the case is affected by many sources of uncertainties. For instance one uncertainty is related to the biomass distribution on the fire pit as also a visual inspection indicates an uneven distribution. Then, the biomass moisture content may also change 
with respect to the proximate analysis because of natural drying. Finally the particle dimensional distribution and shape may also affect results.

Further work will be needed to better control the modeling uncertainties, by for instance implementing more complex kinetics and turbulence-chemistry interaction models, able to handle such kinetics. Then the resulting thermochemical field can be used to estimate NO emissions through post-processing. Since NO formation paths are relatively slow in comparison to fuel oxidation, the calculation is usually based on a finite rate combustion model [34]. However, the distribution of radical species involved in $\mathrm{NO}$ formation, such as $\mathrm{O}$, $\mathrm{OH}$, and $\mathrm{H}$, that may be available by using complex kinetics, may strongly improve the accuracy of predictions. 
423

\section{Nomenclature}

Symbols

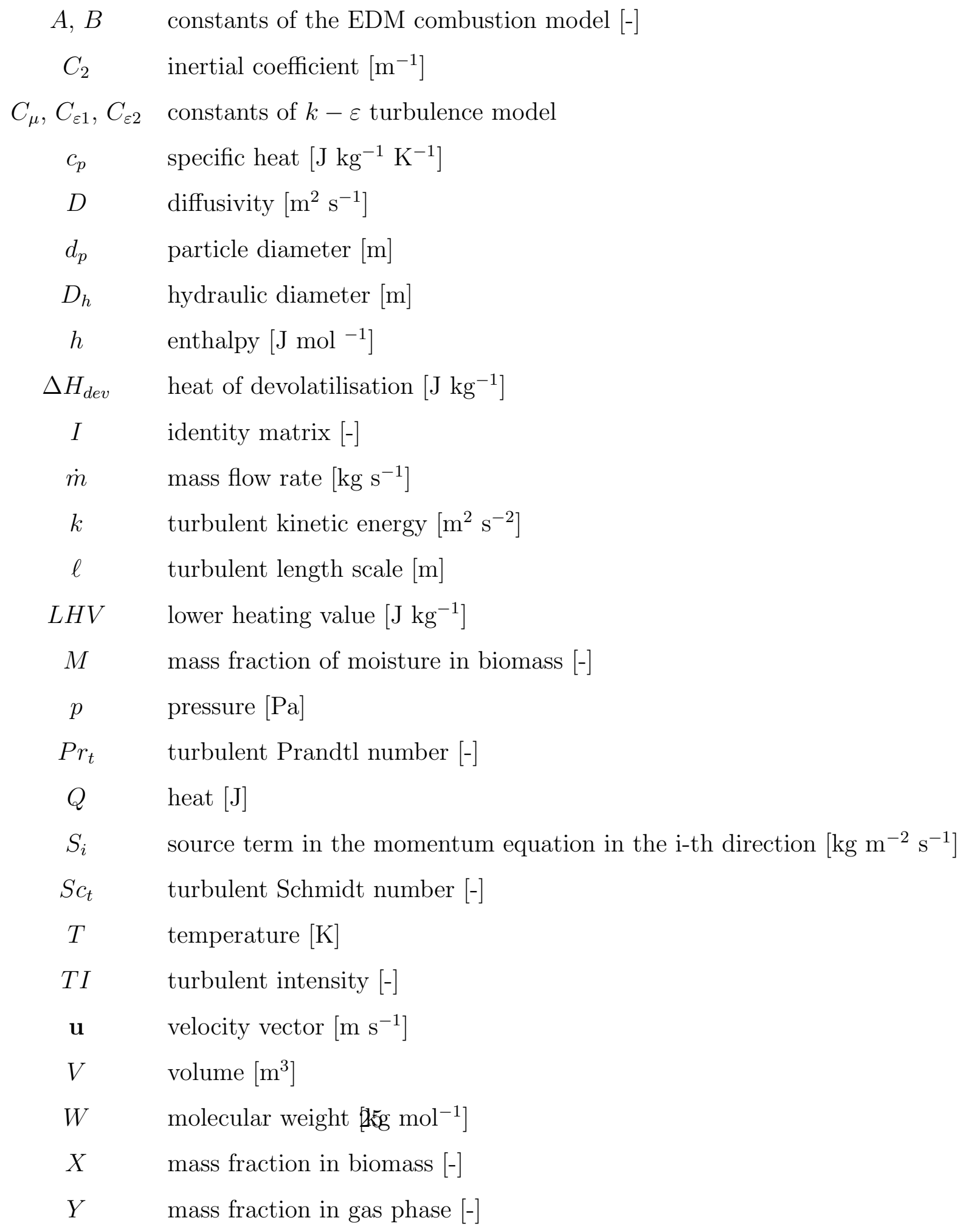


Greek symbols

425

$\begin{array}{ll}\alpha & \text { thermal conductivity }\left[\mathrm{m}^{2} \mathrm{~s}^{-1}\right] \\ \alpha_{p} & \text { permeability of the porous bed }\left[\mathrm{m}^{-2}\right] \\ \epsilon & \text { void fraction }[-] \\ \varepsilon & \text { turbulent dissipation rate }\left[\mathrm{m}^{2} \mathrm{~s}^{-3}\right] \\ \lambda & \text { secondary to primary air flow ratio }[-] \\ \mu & \text { viscosity }\left[\mathrm{kg} \mathrm{m}^{-1} \mathrm{~s}^{-1}\right] \\ \nu^{\prime} & \text { stoichiometric coefficients }[-] \\ \omega & \text { source or sink of a chemical species due to reaction }\left[\mathrm{mol} \mathrm{m}^{-3} \mathrm{~s}^{-1}\right] \\ \rho & \left.\text { density [kg } \mathrm{m}^{-3}\right] \\ \sigma_{k}, \sigma_{\varepsilon} & \text { turbulent Prandtl numbers for } k \text { and } \varepsilon[-] \\ \widetilde{\varphi} & \text { Favre-average of the } \varphi \text { variable }\end{array}$




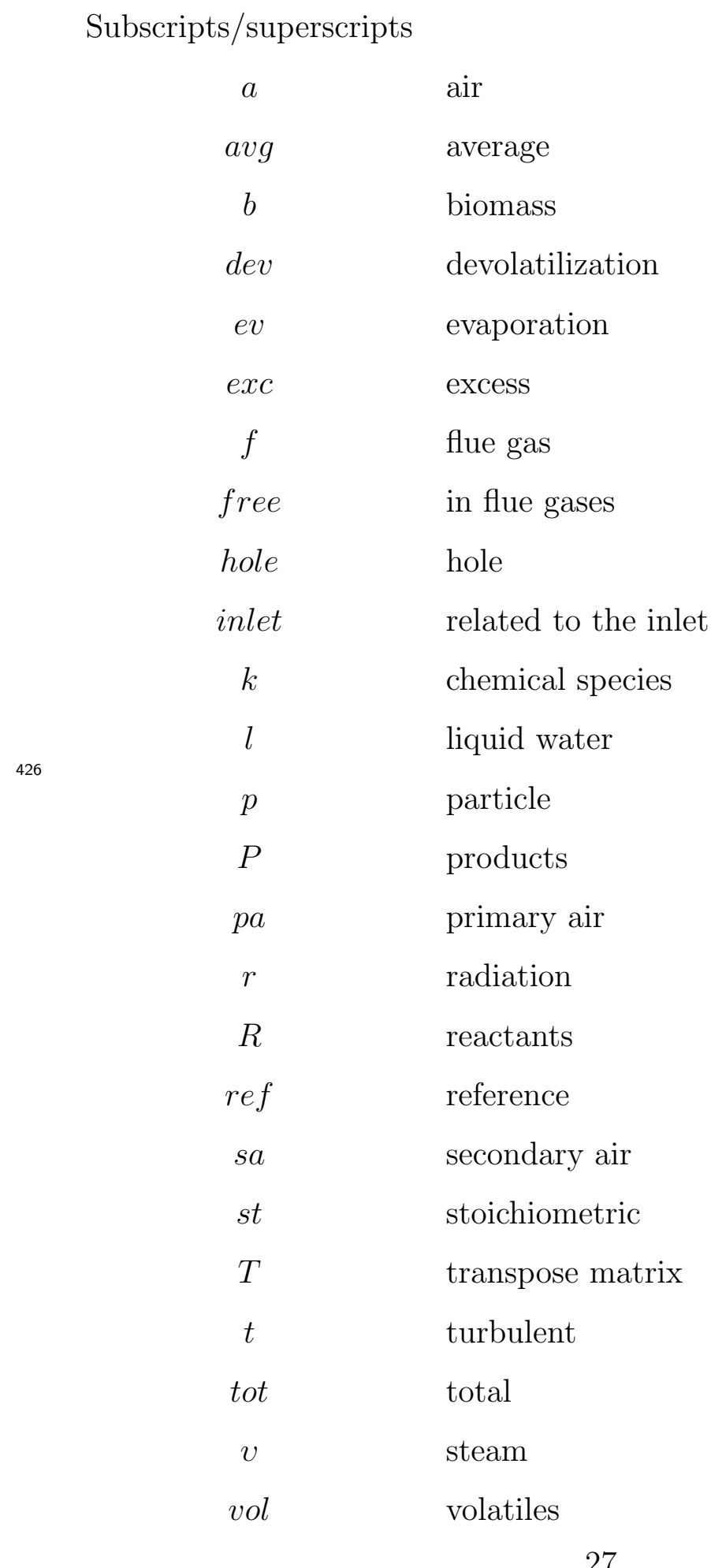




$\begin{array}{cl}\text { Abbreviations } & \\ \text { CFD } & \text { Computational Fluid Dynamics } \\ \text { DEM } & \text { Discrete Element Method } \\ \text { EDC } & \text { Eddy Dissipation Concept } \\ \text { ED/FR } & \text { Eddy Dissipation/Finite Rate } \\ \text { EDM } & \text { Eddy Dissipation Model } \\ \text { PSR } & \text { Perfectly Stirred Reactor }\end{array}$

428

429 430

\section{Acknowledgments}

We are grateful to Dr. Federica Barontini, Ing. Gianluca Caposciutti and Ing. Dario Di Mitri for their help in the experimental campaigns. 


\section{References}

1. Sorrell, S.. Reducing energy demand: a review of issues, challenges and approaches. Renewable and Sustainable Energy Reviews 2015;47:74 $-82$.

2. Demirbas, M.F., Balat, M., Balat, H.. Potential contribution of biomass to the sustainable energy development. Energy Conversion and Management 2009;50(7):1746-1760.

3. Serrano, C., Portero, H., Monedero, E.. Pine chips combustion in a 50kW domestic biomass boiler. Fuel 2013;111:564 - 573.

4. Liu, H., Chaney, J., Li, J., Sun, C.. Control of NOx emissions of a domestic/small-scale biomass pellet boiler by air staging. Fuel $2013 ; 103: 792-798$.

5. Lamberg, H., Sippula, O., Tissari, J., Jokiniemi, J.. Effects of air staging and load on fine-particle and gaseous emissions from a smallscale pellet boiler. Energy \& Fuels 2011;25(11):4952-4960.

6. Wiinikka, H., Gebart, R.. The influence of air distribution rate on particle emissions in fixed bed combustion of biomass. Combustion Science and Technology 2005;177(9):1747-1766.

7. Pettersson, E., Lindmark, F., Ohman, M., Nordin, A., Westerholm, R., Boman, C.. Design changes in a fixed-bed pellet combustion device: Effects of temperature and residence time on emission performance. Energy \&f Fuels 2010;24(2):1333-1340. 
8. Khodaei, H., Guzzomi, F., Yeoh, G.H., Regueiro, A., Patio, D.. An experimental study into the effect of air staging distribution and position on emissions in a laboratory scale biomass combustor. Energy 2017;118:1243 - 1255 .

9. Mohseni, M., Peters, B.. An attempt to study conversion of biomass spheres in a stove using a DEM-CFD approach. Energy Procedia 2017;120:657 - 664 .

10. Mahmoudi, A.H., Markovic, M., Peters, B., Brem, G.. An experimental and numerical study of wood combustion in a fixed bed using eulerlagrange approach (XDEM). Fuel 2015;150:573 - 582.

11. Yin, C., Li, S.. Advancing grate-firing for greater environmental impacts and efficiency for decentralized biomass/wastes combustion. Energy Procedia 2017;120:373 - 379.

12. Gómez, M., Porteiro, J., Patino, D., Míguez, J.. Eulerian CFD modelling for biomass combustion. transient simulation of an underfeed pellet boiler. Energy Conversion and Management 2015;101:666 - 680.

13. Chaney, J., Liu, H., Li, J.. An overview of CFD modelling of smallscale fixed-bed biomass pellet boilers with preliminary results from a simplified approach. Energy Conversion and Management 2012;63:149 $-156$.

14. Scharler, R., Benesch, C., Schulze, K., Obernberger, I.. CFD simulations as efficient tool for the development and optimisation of small- 
scale biomass furnaces and stoves. In: Proceedings of the 19th European Biomass Conference and Exhibition. 2011:.

15. Yin, C., Rosendahl, L., Kær, S.K., Clausen, S., Hvid, S.L., Hille, T.. Mathematical modeling and experimental study of biomass combustion in a thermal 108 MW grate-fired boiler. Energy $\&$ Fuels 2008;22(2):1380-1390.

16. Galletti, C., Giomo, V., Giorgetti, S., Leoni, P., Tognotti, L.. Biomass furnace for externally fired gas turbine: Development and validation of the numerical model. Applied Thermal Engineering 2016;96:372 - 384.

17. Patronelli, S., Caposciutti, G., Barontini, F., Galletti, C., Antonelli, M., Desideri, U., Tognotti, L.. Experimental and numerical investigation of a small-scale fixed-bed biomass boiler. Chemical Engineering Transactions 2017;57:187-192.

18. Porteiro, J., Patio, D., Moran, J., Granada, E.. Study of a fixed-bed biomass combustor: Influential parameters on ignition front propagation using parametric analysis. Energy \& Fuels 2010;24(7):3890-3897.

19. Girgis, E., Hallett, W.L.H.. Wood combustion in an overfeed packed bed, including detailed measurements within the bed. Energy \& Fuels 2010;24(3):1584-1591.

20. Buchmayr, M., Gruber, J., Hargassner, M., Hochenauer, C.. Spatially resolved chemical species concentrations above the fuel bed of a small grate-fired wood-chip boiler. Biomass and Bioenergy 2016;95:146 - 156 . 
21. Buchmayr, M., Gruber, J., Hargassner, M., Hochenauer, C.. A computationally inexpensive CFD approach for small-scale biomass burners equipped with enhanced air staging. Energy Conversion and Management 2016;115:32 - 42.

22. Buchmayr, M., Gruber, J., Hargassner, M., Hochenauer, C.. Performance analysis of a steady flamelet model for the use in small-scale biomass combustion under extreme air-staged conditions. Journal of the Energy Institute 2017;.

23. Caposciutti, G., Antonelli, M.. Experimental investigation on air displacement and air excess effect on $\mathrm{CO}, \mathrm{CO} 2$ and $\mathrm{NOx}$ emissions of a small size fixed bed biomass boiler. Renewable Energy 2018;116(Part A):795 - 804 .

24. Caposciutti, G., Barontini, F., Francesconi, M., Antonelli, M.. Experimental investigation on the fixed bed of a small size biomass boiler. Energy Procedia 2017;142:468 - 473.

25. Tognotti, L., Longwell, J., Sarofim, A.. The products of the high temperature oxidation of a single char particle in an electrodynamic balance. Symposium (International) on Combustion 1991;23(1):1207 1213.

26. Zhang, X., Chen, Q., Bradford, R., Sharifi, V., Swithenbank, J.. Experimental investigation and mathematical modelling of wood combustion in a moving grate boiler. Fuel Processing Technology 2010;91(11):1491 - 1499 . 
27. Collazo, J., Porteiro, J., Míguez, J., Granada, E., Gómez, M.. Numerical simulation of a small-scale biomass boiler. Energy Conversion and Management 2012;64:87 - 96.

28. Scharler, R., Fleckl, T., Obernberger, I.. Modification of a magnussen constant of the eddy dissipation model for biomass grate furnaces by means of hot gas in-situ FT-IR absorption spectroscopy. Progress in Computational Fluid Dynamics 2003;3(2-4):102-111.

29. Bugge, M., Skreiberg, O., Haugen, N.E.L., Carlsson, P., Houshfar, E., Løvås, T.. Numerical simulations of staged biomass grate fired combustion with an emphasis on NOx emissions. Energy Procedia 2015;75:156 $-161$.

30. Shiehnejadhesar, A., Scharler, R., Mehrabian, R., Obernberger, I.. Development and validation of cfd models for gas phase reactions in biomass grate furnaces considering gas streak formation above the packed bed. Fuel Processing Technology 2015;139:142 - 158.

31. Smith, T.F., Shen, Z.F., Friedman, J.N.. Evaluation of coefficients for the weighted sum of gray gases model. ASME Journal of Heat Transfer 1982;104:602-608.

32. Hall, M.J., Hiatt, J.P.. Measurements of pore scale flows within and exiting ceramic foams. Experiments in Fluids 1996;20(6):433-440.

33. Ergun, S.. Fluid flow through packed columns. Chemical Engineering Progress 1952;48:89-94. 
542 34. Parente, A., Galletti, C., Tognotti, L.. A simplified approach for predicting NO formation in MILD combustion of $\mathrm{CH}_{4}-\mathrm{H}_{2}$ mixtures. Pro-

544 ceedings of the Combustion Institute 2011;33(2):3343 - 3350. 


\section{List of Figures}

1 Scheme of: (a) experimental plant of CRIBE; (b) combustion chamber; (c) secondary air injection. . . . . . . . . . . . 37

2 Position of thermocouples on the fire pit. . . . . . . . . 38

3 Combustion chamber (a) geometry and (b) computational grid. 39

4 Detail of (a) porous bed geometry and (b) computational grid for CFD model \#3 . . . . . . . . . . . . . . . . . . 40

5 Distribution of temperature on the boiler symmetry (i.e. longitudinal mid-plane) predicted with (a) CFD model \#1,(b) CFD model \#2 (c) CFD model \#3. Experimental test \#1 of Table 2. . . . . . . . . . . . . . . . . . . . . . 4 41

6 Distribution of temperature at different cross-sections predicted with (a) CFD model \#1,(b) CFD model \#2 (c) CFD model \#3. Experimental test \#1 of Table 2. . . . . . . . . . . 42

$7 \quad 3 \mathrm{D}$ maps of the bed surface temperature predicted with (a) CFD model \#1,(b) CFD model \#2 (c) CFD model \#3, and experimental temperatures (solid symbols: $r$ hombi $=$ central thermocouples, squares $=$ lateral thermocouples). Experimental test \#1 of Table 2. . . . . . . . . . . . . . . . . 43

8 Distribution of temperature on the boiler symmetry (i.e. longitudinal mid-plane) predicted with CFD model \#3 at different secondary to primary air flow rate ratios: (a) $\lambda=0.6$,(b) $\lambda=0.8$ (c) $\lambda=1 \ldots \ldots \ldots \ldots \ldots \ldots \ldots$

9 Distribution of temperature at different cross sections in the boiler predicted with CFD model \#3 for different secondary to primary air flow rate ratios: (a) $\lambda=0.6$,(b) $\lambda=0.8$ (c) $\lambda=1 \ldots \ldots \ldots \ldots \ldots \ldots \ldots \ldots \ldots$

103 D maps of the bed surface temperature predicted with CFD model \#3 and experimental temperatures (solid symbols: rhombi $=$ central thermocouples, squares $=$ lateral thermocouples) for different secondary to primary air flow rate ratios: (a) $\lambda=0.6$, (b) $\lambda=0.8$ and (c) $\lambda=1 \ldots \ldots \ldots \ldots$

11 Comparison between experimental and predicted temperatures for different secondary to primary air flow rate ratios $\lambda$ and locations (see Figure 2): (a) HL, (b) HC, (c) HR, (d) LL, (e) LC and (f) LR. . . . . . . . . . . . . . . . . . . . 47 
12 Comparison between experimental measurements of (a) temperature, (b) $\mathrm{O}_{2}$ mass fraction, (c) $\mathrm{CO}_{2}$ mass fraction and those predicted with the CFD model \#3 for different secondary to primary air flow ratios. . . . . . . . . . . . . . 48 


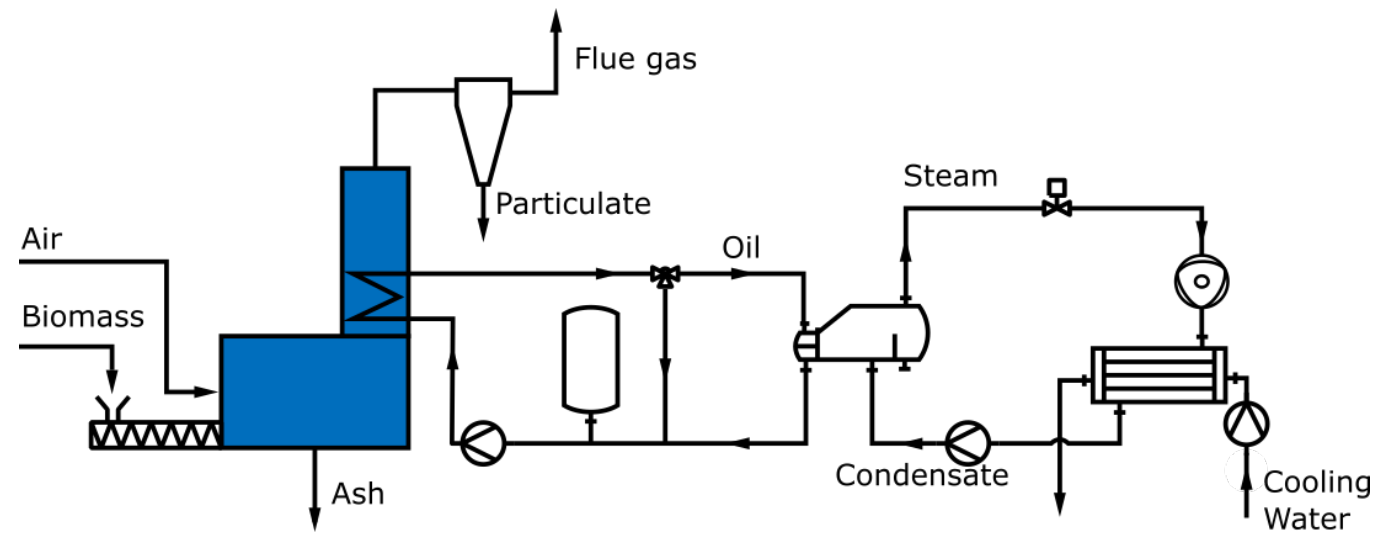

(a)

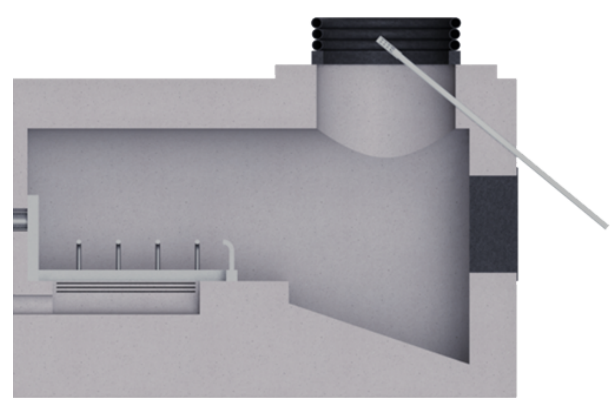

(b)

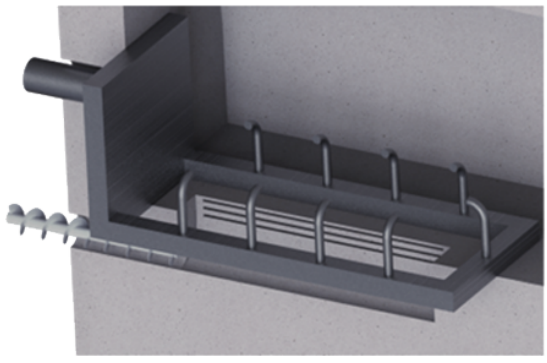

(c)

Figure 1: Scheme of: (a) experimental plant of CRIBE; (b) combustion chamber; (c) secondary air injection. 


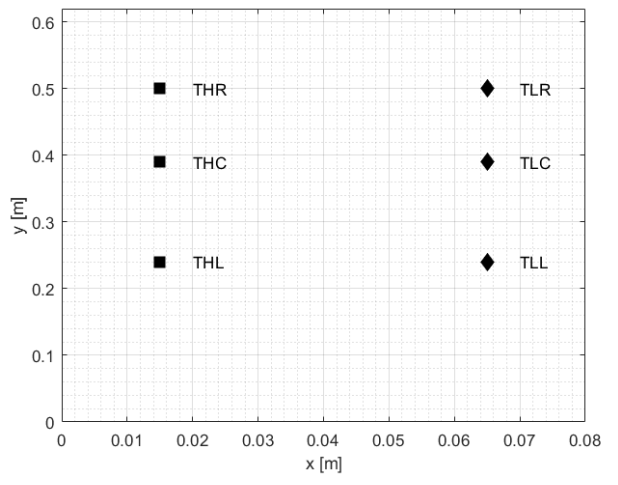

Figure 2: Position of thermocouples on the fire pit. 


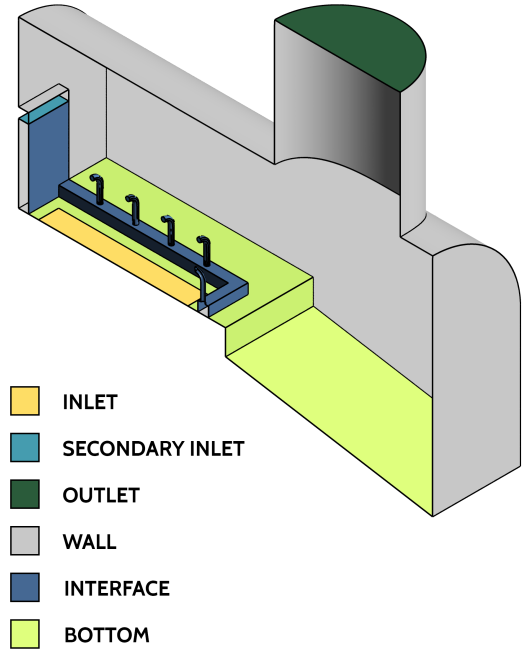

(a)

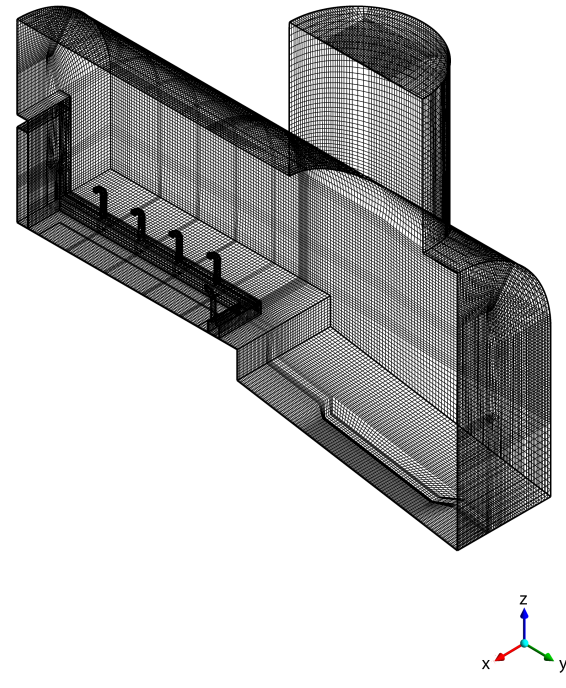

(b)

Figure 3: Combustion chamber (a) geometry and (b) computational grid. 


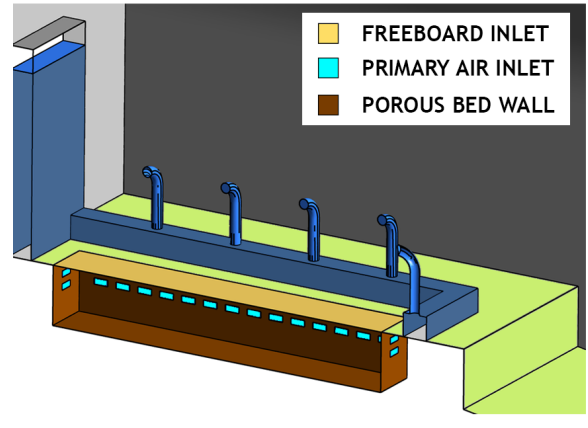

(a)

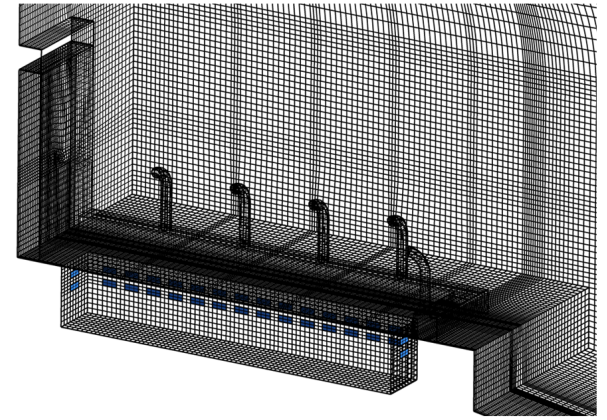

(b)

Figure 4: Detail of (a) porous bed geometry and (b) computational grid for CFD model \#3 


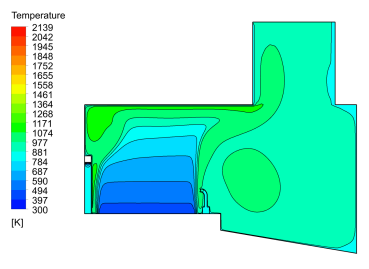

(a)

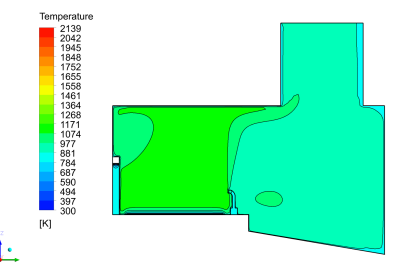

(b)

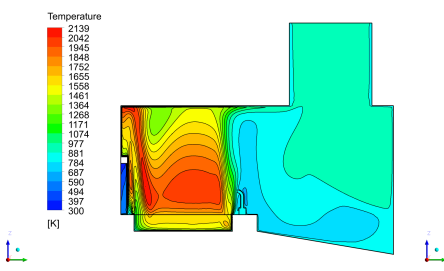

(c)

Figure 5: Distribution of temperature on the boiler symmetry (i.e. longitudinal mid-plane) predicted with (a) CFD model \#1,(b) CFD model \#2 (c) CFD model \#3. Experimental test \#1 of Table 2. 


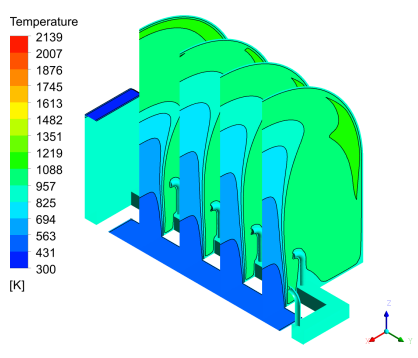

(a)

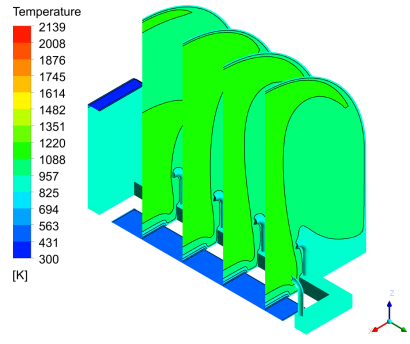

(b)

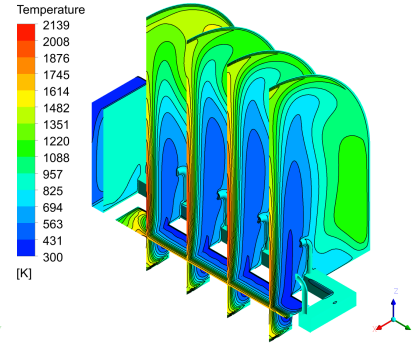

(c)

Figure 6: Distribution of temperature at different cross-sections predicted with (a) CFD model \#1,(b) CFD model \#2 (c) CFD model \#3. Experimental test \#1 of Table 2. 


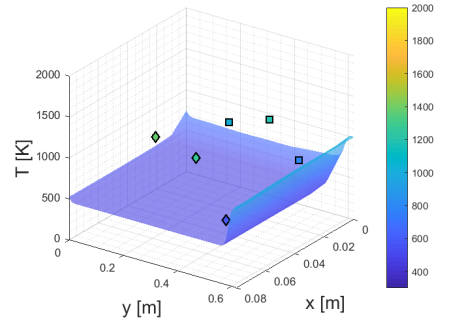

(a)

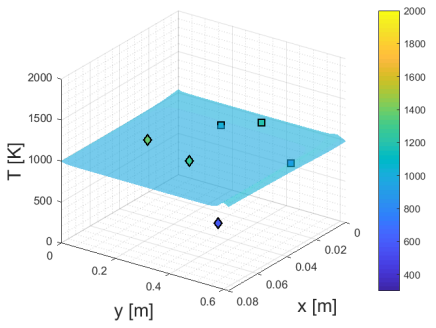

(b)

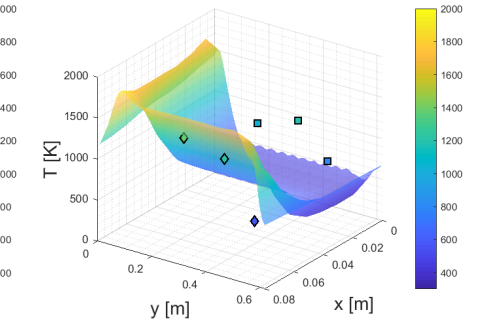

(c)

Figure 7: 3D maps of the bed surface temperature predicted with (a) CFD model \#1,(b) CFD model \#2 (c) CFD model \#3, and experimental temperatures (solid symbols: rhombi $=$ central thermocouples, squares $=$ lateral thermocouples). Experimental test \# 1 of Table 2 . 


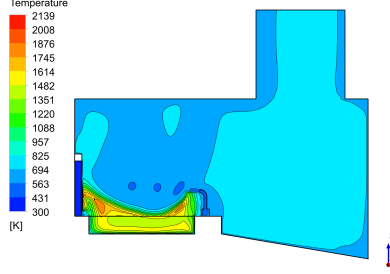

(a)

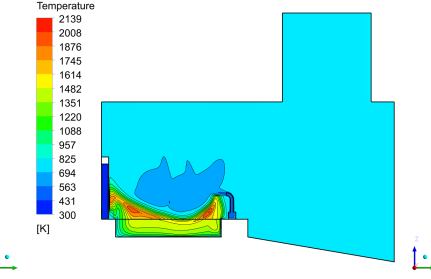

(b)

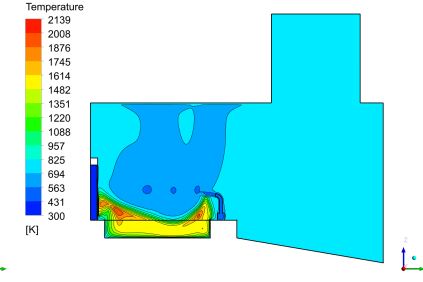

(c)

Figure 8: Distribution of temperature on the boiler symmetry (i.e. longitudinal mid-plane) predicted with CFD model \#3 at different secondary to primary air flow rate ratios: (a) $\lambda=0.6$,(b) $\lambda=0.8$ (c) $\lambda=1$. 


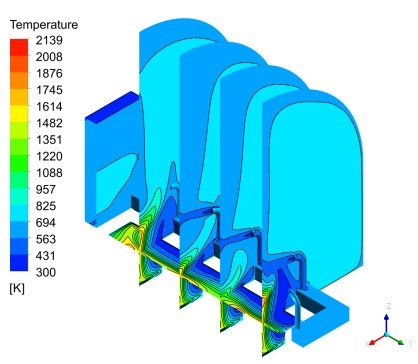

(a)

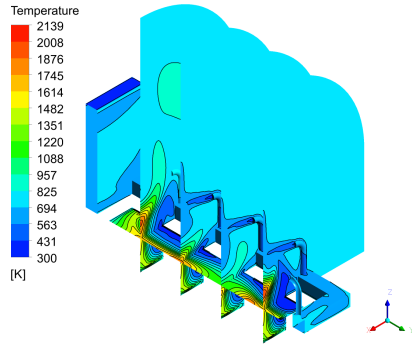

(b)

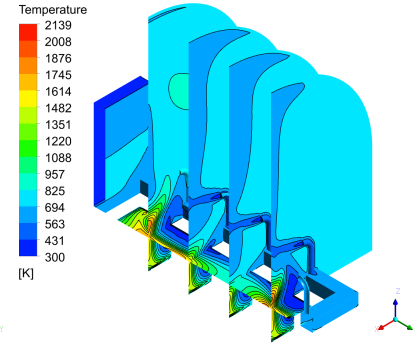

(c)

Figure 9: Distribution of temperature at different cross sections in the boiler predicted with CFD model \#3 for different secondary to primary air flow rate ratios: (a) $\lambda=0.6$ ,(b) $\lambda=0.8$ (c) $\lambda=1$. 


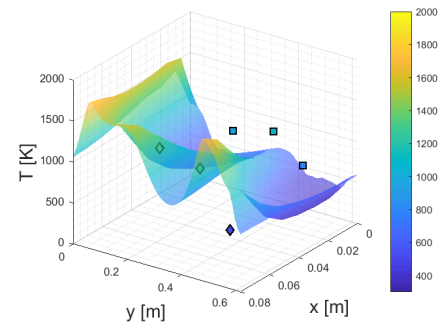

(a)

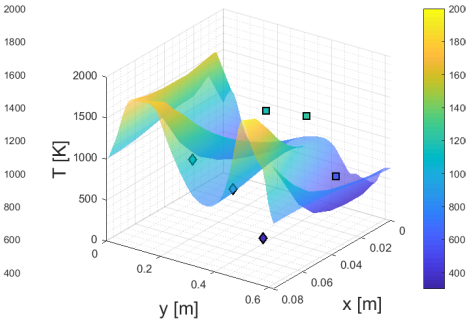

(b)

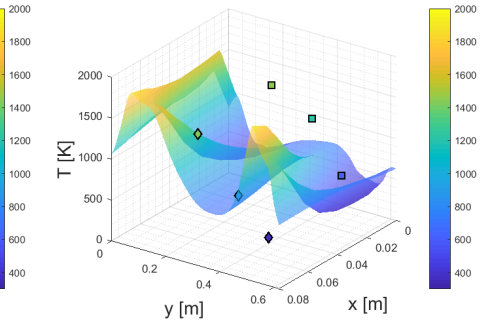

(c)

Figure 10: 3D maps of the bed surface temperature predicted with CFD model \#3 and experimental temperatures (solid symbols: rhombi $=$ central thermocouples, squares $=$ lateral thermocouples) for different secondary to primary air flow rate ratios: (a) $\lambda=0.6$, (b) $\lambda=0.8$ and (c) $\lambda=1$. 


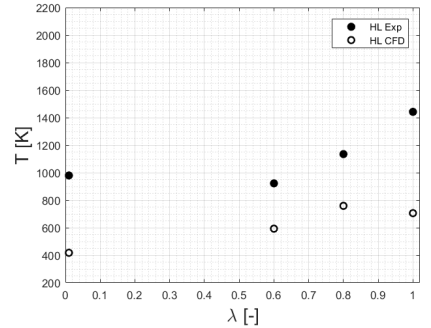

(a)

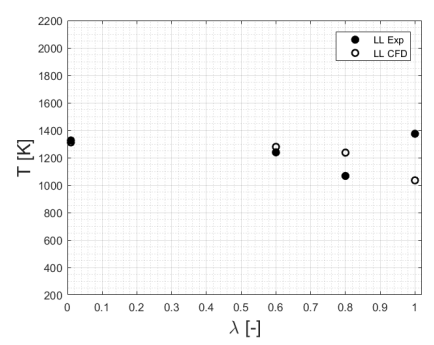

(d)

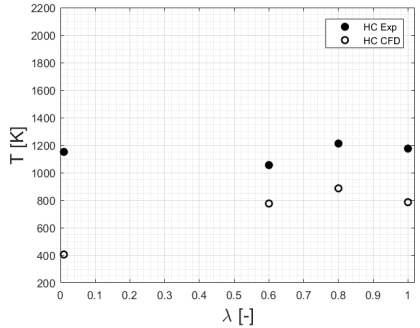

(b)

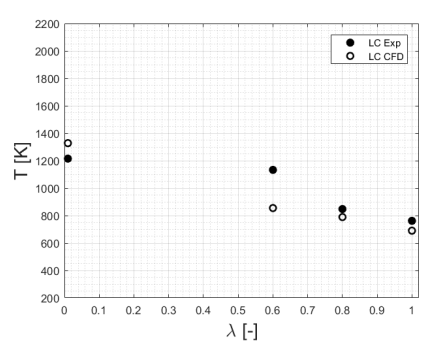

(e)

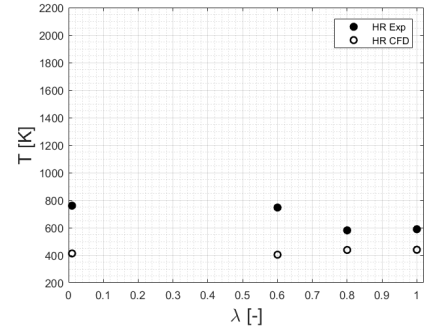

(c)

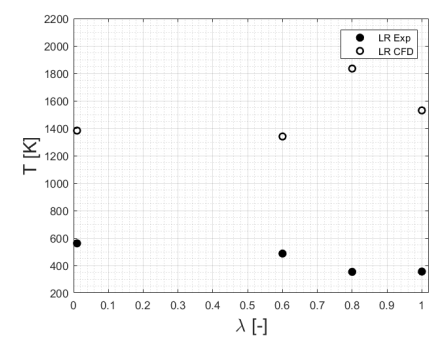

(f)

Figure 11: Comparison between experimental and predicted temperatures for different secondary to primary air flow rate ratios $\lambda$ and locations (see Figure 2): (a) HL, (b) HC, (c) HR, (d) LL, (e) LC and (f) LR. 


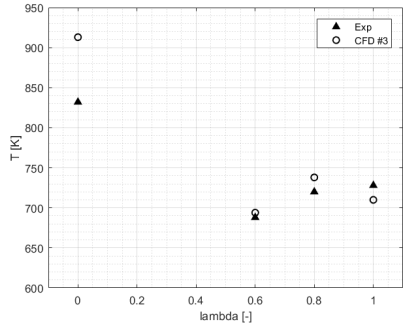

(a)

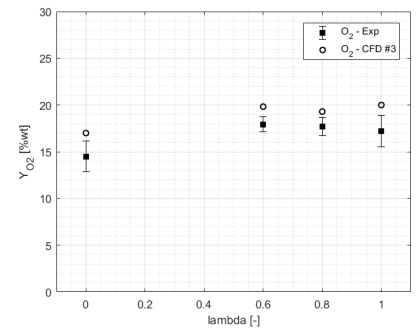

(b)

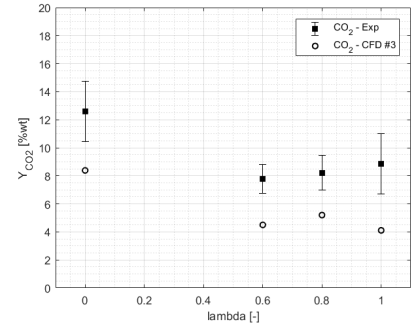

(c)

Figure 12: Comparison between experimental measurements of (a) temperature, (b) $\mathrm{O}_{2}$ mass fraction, (c) $\mathrm{CO}_{2}$ mass fraction and those predicted with the CFD model \#3 for different secondary to primary air flow ratios. 


\section{List of Tables}

1 Ultimate and proximate analyses of the poplar wood-chips. . . 50

2 Operative conditions and emissions in combustion tests of poplar wood-chips. . . . . . . . . . . . . . 51

3 Average experimental temperatures measured above the bed for different secondary to primary air flow ratios. Thermocouple positions are shown in Figure 2. . . . . . . . . . . . . . . 52

4 Source terms employed in the UDF sub-routine for model \#3. 53 
Table 1: Ultimate and proximate analyses of the poplar wood-chips.

\begin{tabular}{llllll}
\hline Ultimate Analysis & {$[\% \mathrm{wt}($ dry) $]$} & Proximate Analysis & {$[\%$ wt $($ wet $)]$} & Fuel Parameters & \\
\hline Carbon & 48.95 & Moisture & 9.84 & Particle Size $d_{p}[m]$ & 0.013 \\
Hydrogen & 5.95 & Ash & 1.60 & Void Fraction $\varepsilon$ & 0.5 \\
Oxygen & 44.64 & Fixed Carbon & 12.02 & & \\
Nitrogen & 0.46 & Volatile Matter & 76.54 & $L H V$ as received $\left[\frac{\mathrm{MJ}}{\mathrm{kg}}\right]$ & 18.41 \\
\hline
\end{tabular}


Table 2: Operative conditions and emissions in combustion tests of poplar wood-chips.

\begin{tabular}{cccccccccc}
\hline Test & $\begin{array}{c}\dot{m}_{b} \\
{\left[\mathrm{~kg} \mathrm{~s}^{-1}\right]}\end{array}$ & $\begin{array}{c}\dot{m}_{a, t o t} \\
{\left[\mathrm{~kg} \mathrm{~s}^{-1}\right]}\end{array}$ & $\begin{array}{c}\dot{m}_{p a} \\
{\left[\mathrm{~kg} \mathrm{~s}^{-1}\right]}\end{array}$ & $\begin{array}{c}\lambda \\
{[-]}\end{array}$ & $\begin{array}{c}T_{f} \\
{[\mathrm{~K}]}\end{array}$ & $\begin{array}{c}\mathrm{O}_{2} \\
{[\% \mathrm{wt}]}\end{array}$ & $\begin{array}{c}\mathrm{CO}_{2} \\
{[\% \mathrm{wt}]}\end{array}$ & $\begin{array}{c}\mathrm{CO} \\
{[\mathrm{ppm}]}\end{array}$ & $\begin{array}{c}\mathrm{NO}_{x} \\
{[\mathrm{ppm}]}\end{array}$ \\
\hline$\# 1$ & 0.0057 & 0.10 & $0.0998^{ \pm 0.0007}$ & - & $832^{ \pm 1}$ & $14.5^{ \pm 1.67}$ & $12.6^{ \pm 2.16}$ & $335^{ \pm 206}$ & $18.79^{ \pm 2.4}$ \\
$\# 2$ & 0.0033 & 0.10 & $0.0650^{ \pm 0.001}$ & $0.588^{ \pm 0.02}$ & $688^{ \pm 0.7}$ & $17.9^{ \pm 0.8}$ & $7.8^{ \pm 1.04}$ & $1603^{ \pm 327}$ & $12.96^{ \pm 2.08}$ \\
$\# 3$ & 0.0035 & 0.10 & $0.0560^{ \pm 0.003}$ & $0.793^{ \pm 0.09}$ & $720^{ \pm 0.7}$ & $17.6^{ \pm 0.9}$ & $8.22^{ \pm 1.25}$ & $1339^{ \pm 248}$ & $13.33^{ \pm 1.69}$ \\
$\# 4$ & 0.0038 & 0.10 & $0.0546^{ \pm 0.002}$ & $0.980^{ \pm 0.06}$ & $728^{ \pm 0.7}$ & $17.2^{ \pm 1.6}$ & $8.84^{ \pm 2.15}$ & $1341^{ \pm 307}$ & $13.80^{ \pm 2.12}$ \\
\hline
\end{tabular}


Table 3: Average experimental temperatures measured above the bed for different secondary to primary air flow ratios. Thermocouple positions are shown in Figure 2.

\begin{tabular}{cccccccc}
\hline Test & $\lambda$ & $T_{H R}$ & $T_{L R}$ & $T_{H C}$ & $T_{L C}$ & $T_{H L}$ & $T_{L L}$ \\
& {$[-]$} & {$[\mathrm{K}]$} & {$[\mathrm{K}]$} & {$[\mathrm{K}]$} & {$[\mathrm{K}]$} & {$[\mathrm{K}]$} & {$[\mathrm{K}]$} \\
\hline$\# 1$ & - & $760^{ \pm 110}$ & $561^{ \pm 31}$ & $1151^{ \pm 100}$ & $1215^{ \pm 107}$ & $980^{ \pm 2.4}$ & $1325^{ \pm 37}$ \\
$\# 2$ & $0.588^{ \pm 0.02}$ & $746^{ \pm 58}$ & $486^{ \pm 22}$ & $1055^{ \pm 104}$ & $1133^{ \pm 90}$ & $922^{ \pm 2.08}$ & $1238^{ \pm 37}$ \\
$\# 3$ & $0.793^{ \pm 0.09}$ & $581^{ \pm 15}$ & $353^{ \pm 1.8}$ & $1212^{ \pm 71}$ & $848^{ \pm 131}$ & $1135^{ \pm 2.08}$ & $1067^{ \pm 205}$ \\
$\# 4$ & $0.980^{ \pm 0.06}$ & $589^{ \pm 3}$ & $355^{ \pm 0.2}$ & $1176^{ \pm 106}$ & $762^{ \pm 70}$ & $1442^{ \pm 2.08}$ & $1374^{ \pm 493}$ \\
\hline
\end{tabular}


Table 4: Source terms employed in the UDF sub-routine for model \#3.

\begin{tabular}{lrrrr}
\hline Source Terms & Test \#1 & Test \#2 & Test \#3 & Test \#4 \\
\hline $\mathrm{V}\left[\mathrm{m}^{3}\right]$ & 0.0048 & 0.0048 & 0.0048 & 0.0048 \\
$\mathrm{Vol}\left[\mathrm{kg} \mathrm{m}^{-3} \mathrm{~s}^{-1}\right]$ & 0.46 & 0.27 & 0.28 & 0.305 \\
$\mathrm{H}_{2} \mathrm{O}[\mathrm{kg}]$ & 0.059 & 0.034 & 0.036 & 0.039 \\
$\mathrm{CO}_{2}\left[\mathrm{~kg} \mathrm{~m}^{-3} \mathrm{~s}^{-1}\right]$ & 0.264 & 0.153 & 0.162 & 0.176 \\
$\mathrm{O}_{2}\left[\mathrm{~kg} \mathrm{~m}^{-3} \mathrm{~s}^{-1}\right]$ & -0.191 & -0.111 & -0.118 & -0.128 \\
Energy $\left[\mathrm{W} \mathrm{m}^{-3}\right]$ & 94859 & 54918 & 58247 & 63240 \\
Radiation $\left[\mathrm{W} \mathrm{m}^{-3}\right]$ & 252 & 162 & 155 & 143 \\
\hline
\end{tabular}

